\title{
C-R-D Risk and Measurement Model of Complex Supply Chain Network in Industry Cluster
}

\author{
Haiju $\mathrm{Hu}^{1}$, Shu $\mathrm{Bo}^{2 *}$ and Wang Peng ${ }^{3}$ \\ ${ }^{1}$ Economics and Management School, Yanshan University, Qinhuangdao, \\ China, 066004 \\ ${ }^{2}$ Economics and Management School, Yanshan University, Qinhuangdao, \\ China, 066004 \\ ${ }^{3}$ School of Liren, Yanshan University, Qinhuangdao, China, 066004 \\ ${ }^{1}$ huhaiju@ysu.edu.cn, ${ }^{2}$ shubo@ysu.edu.cn, ${ }^{3}$ wangpeng198111@ysu.edu.cn
}

\begin{abstract}
Industry cluster and complex network of supply chain are frontier theoretical issues. Based on literature review, this study explains $C-R-D$ risk of complex network of supply chain in industry cluster, and puts forward congestion risk, rigescence risk, decline risk and their transmission mechanism. Considering in the perspective of network evolution, there exists mutual and enhancing transmission mechanism among the three kinds of risks. Meanwhile, DRSC measurement model is established based on the theory of complex network, which can reflect the risk influence on complex network of supply chain in industry cluster; node congestion degree, channels congestion degree and same industry suppliers congestion degree are brought forward in order to measure the degree of congestion risk; external occlusion degree and inner occlusion degree are established in order to measure the degree of rigescence risk; average rate of decline and scale in network are defined in order to measure the degree of decline risk. Based on 87network of supply chain in a given industry cluster.
\end{abstract}

Keywords: Industry clusters; Complex network of supply chain; C-R-D Risk; DRSC Measurement Model

\section{Introduction}

The problem of industrial cluster and supply chain risk has attract much attention in the field of industry research. Lots of research focused on the sources of risk, transmission mechanism, countermeasures, and so forth. Classification of the risk in supply chain or industry cluster has become the mainstream foundation with the perspective of tracing to the source. The influence factors of the risk, however, are so interweaved that it is difficult to distinguish the effect of the factors. Meantime, too many ambiguities exist in the research of overall effect and transmitting mechanism. Therefore, we attempts to study the risk influence effect of the industry cluster from the perspectives of supply chain according to the theory of complex network.

\section{Literature Review}

Being the highly abstract of a large number of real complex systems, complex network has become a new hot topic of academic research in recent years. In the field of supply chain, with the theory of complex network, Dirk Helbing (2006)

${ }^{*}$ Corresponding Author 
believed that supply chain belongs to a complex network system which has the characteristics of self-organization, emergence, nonlinear, dynamics and evolution. It is confirmed that there is a close relationship between the bullwhip effect in supply chain and the properties of topological structure of supply chain. A good supply chain structure not only can weaken the bullwhip effect, but also can increase the stability of the supply chain. Marco Laumanns and Erjen Lefeber(2006) stimulated the evolution of supply chain network by means of first order differential equations and found the optimal solution using robust optimal control. Christian Kuhnert (2006) considered that the core nodes are in the minority, but play an important role in supplies scheduling and distribution. Jinli Guo (2006) analyzed the essential features of the supply chain network and proved that it is a directed network and the arrival process of the nodes is a refresh process with the new number of in-edges and out-edges randomly and Bernoulli distributed. They studied the distribution of transient degree and steady average degree. Xinrui Zhang and Hengshan Wang (2008) established the model of complex supply chain structure.

According to the content of interactive relation between organizations in the research of industry cluster, Tichy (1998) classified the industry cluster as input-output network, labor network, technical cooperation network which include the interaction between organizations for production, labor and technology aspects, and relationship of cooperation or contest. Cai, et. al., (2006), by analyzing the network structure of industry cluster, found that characteristics of network structure of industry cluster heavily influenced the ability of integrated resources and network of cluster had the self capacity to resist risk. With the scale-free characteristic, the capacity has the dual characteristic of robustness and vulnerability. Wang (2008) studied the innovation capacity, innovation system, innovation mechanism and performance, innovation risk respectively.

In the field of risk research of supply chain network and industry cluster, Ritehie (2000) believed that most linear relationship model of supply chain would be substituted as the more complex and more disordered relationship model. Harland C., et. al., (2003) regarded the supply chain as supply network and summarized nine kinds of supply chain risks which would influence the operation and environment of supply chain network. Cavinato (2004) analyzed the sources of supply chain risk from five aspects: logistics, capital flow, information flow, relation network and innovation network. From the perspective of probability of risk events and results. Jukka et. al., (2004) put forward the general structure of supplier network and management measures with complex network environment. Saxenian and Anna Lee (1994) compared the IT industry cluster in Silicon Valley and the 128 road area because of their closely geographical locations and similar techniques, and believed that factors such as local society culture, society system and industry system are different, which is the root cause that the enterprises network in Silicon Valley is flourishing while in the 128 road area is declining. Markuen believed that cluster would gradually be a bounded system because of the specialization, which will lead to rigidification of cluster and become enervated, because of lacking the essential information. Cai, et. al., (2003) studied the risk of industry cluster network, meanwhile analyzed the network risk and structure risk. Ning Cai and Mengzhou Xu (2008) put forward the peculiar failure phenomenon: dilemma of industry network scale, dilemma of society relationship and dilemma of supporting section, then they discussed the policy of clusters management. Faming Wang and Chuangeng Liu (2009) tudied the valuables of clusters complex network and their influence to industry risk. Chen, et. al., (2015) argued that the structure of the industrial cluster network can influence the anti-risk capbility of innoavation network of cluster.

Based on research above, three research areas must be further studied. Firstly, tracing to the sources is the mainstream of research perspective to explain the supply 
chain risk and industry cluster risk. There are too many definitions on risk, but all lack research oriented the influence result. For example, Ernst and Young's (2003) survey found that there are eight kinds of risks: risk of business continuity planning, data integrity risk, application security risk of supply chain management technology, corporate governance risk, cooperation risk, supply chain management and invest risk, labor risk and tax risk. Based on the supply network theory, Harland (2003) put forward nine kinds of risks: strategic risk, operation risk, supply risk, customers risk, Asset damage risk, contest risk, credit risk, tax risk, system risk, law risk. Above all, the basis and definitions are different, but they usually based on the cause of the risk. Classification in industry cluster is almost unified, and the source of the risk concludes internal and external factors form behaved cyclical risk, structural risk, network risk and self twist risk etc., enhanced each other. Like the risk of supply chain, research into risk of industry clusters is also focused on cause analysis. Therefore, if it based on the resulted-perspective, the research can confirm the result of the former, measure the influence degree of the risk, however, few has been done currently.

Secondly, complex network theory is an important research methodology to study the phenomenon of network as a whole. As mentioned above, complex network theory has been applied to the research of industry cluster and supply chain management, but there are a few research results. In fact, the theory of fragility, robustness and congestion can be taken and transplanted, and the research views the measurement of complex network risk as a whole.

Thirdly, the further research on supply chain risk in industry cluster needs an in-depth study. Senett and Simmie put forward that innovative industry cluster is that enterprises highly cooperate by means of supply chain on the condition of the same market environment. Van De Berg believed that industry cluster should be located as a local network with specialized organization, which makes the production process connected closely by product, service and knowledge communication.

Therefore, industry cluster is not only a presentation of geographical sense of the cluster- similar of position, but also concludes cooperation among enterprises, relation of similar, which present characteristics of local complex network. There are, however, a lot of things to do with the complex network theory in the risk research areas of the supply chain in industry cluster.

\section{C-R-D Risk Model of Supply Chain in Industry Cluster and Transmission Mechanism}

\subsection{Definition of Supply Chain Network in Industry Cluster}

Supply chain network in industry cluster is a concept of contingency between industry cluster and supply chain. It can be described as a kind of network of enterprises in industry cluster with focuses from the perspective of relationship of supply and demand, or a kind of supply chain network being studied in local scope of industry cluster. As shown in Figure 1, ${ }^{A_{01}},{ }^{A_{02}},{ }^{A_{03}}$ present material supply enterprises in industry cluster in area, ${ }_{i j},{ }^{C_{i j}}, D_{i j}$ indicate node enterprises of supply chain in area ${ }^{i}$ (downstream enterprises of $A_{01}, A_{02}, A_{03}$ ). Among which $i=0,1,2$ respectively present area I, II, III; ${ }^{j}$ represents different node enterprises; arrows indicate the relationship of logistic supply. In Figure 1, though node enterprises of ${ }^{B_{11}},{ }^{C}{ }_{11},{ }^{D_{23}}$ in area II and area III exist the demand and supply relationship with area I, the supply chain network in the industry cluster does not 
conclude the node enterprises in other areas, namely, in figure 1, the geographical scale of research object of supply chain network risk in industry cluster is the scale of the double dotted line. Therefore the research will based on the complex supply chain network theory, from the perspective of presentation and evolution of complex network structure study the risk limited to the enterprises network of supply chain relationship in special area where the industry cluster locates.

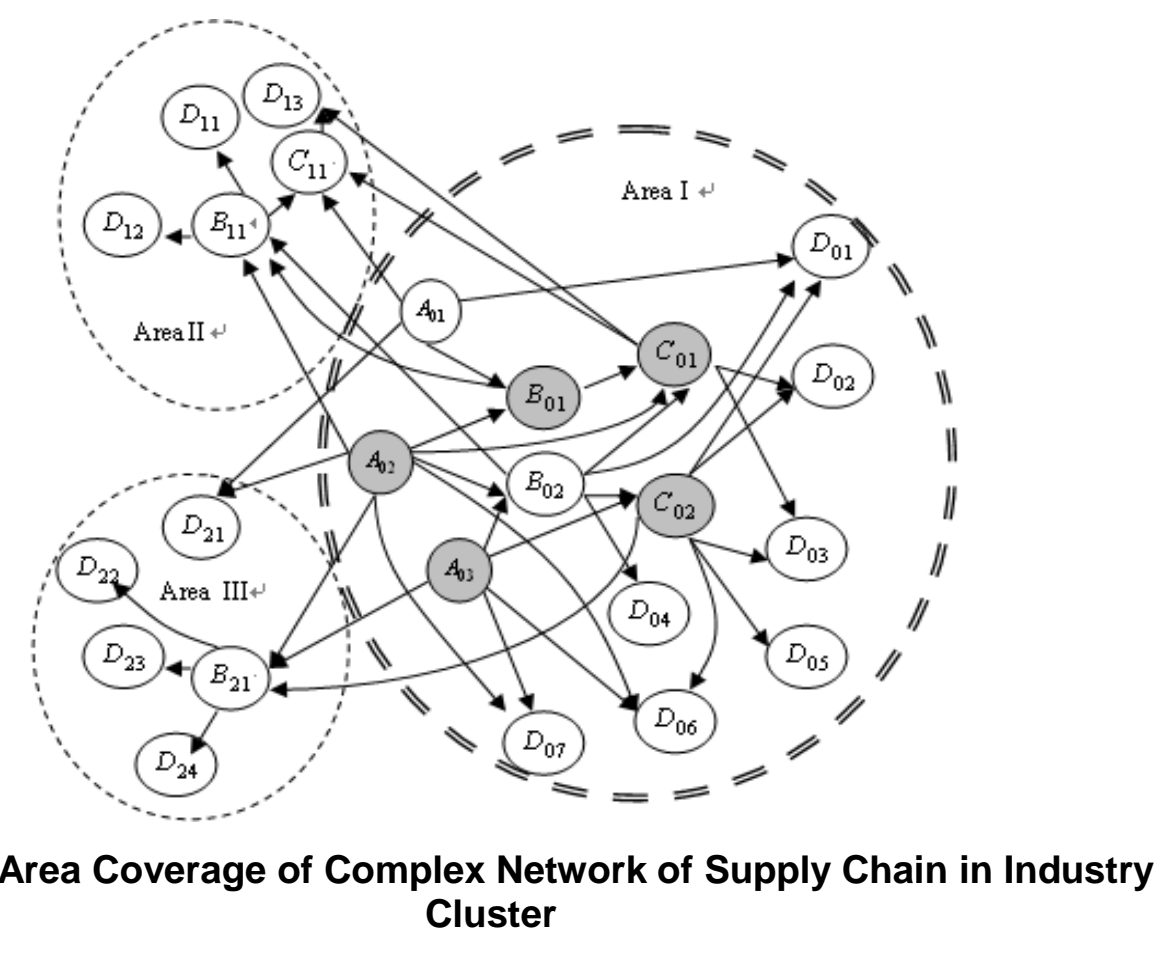

\subsection{C-R-D risk of Complex Supply Chain in Industry Cluster}

Risk, conducted by supply chain network in industry cluster, leads to the immigration of supply chain complex network structure, size and efficiency. There are three kinds of risks, Congestion Risk, Rigescence Risk and Decline Risk from the perspective of presentation and evolution of supply chain network, which are called C-R-D risk. These are explained as follows:

\subsubsection{Congestion Risk}

In industry cluster, congestion is a cluster phenomenon of business volumes which take place in node enterprises or network channel of complex supply chain network. Transmit capacity of every channel is limited because of the limited volume of business of every node, and the transmit capacity of logistic flow and information flow is decided by the volume of business of the bottleneck node enterprises, which determines the limitation of overall business volume of complex supply chain network. If the business volume from external input is more than the volume that the supply chain network can deal with, or the volume which an upstream enterprise transmits is more than the volume which a downstream enterprise can accept, with the subsequent transmitting, the accumulation phenomenon will arise. We call this phenomenon congestion. Congestion risk is a risk caused by congestion. So in this paper, congestion risk is caused by a network state of lasting overloaded in supply chain network in industry cluster. Specifically, congestion risk can be divided as logistic congestion risk, capital risk and communication risk, according to types of transmitting media. Congestion risk also 
can be divided as node congestion risk, channels congestion risk and the same tier supplier congestion risk. For example, supply exceeds demand in industry cluster can lead to node and logistic congestion risk. If the supplier produced lots of products more than the customers' order, supplier product flow congestion risk would occur. If the customers ordered material too much from many suppliers, customer material congestion risk would arise. Bullwhip effect is obvious on the influential effect of information congestion risk. From the supplier's view, bullwhip effect is the results of different tiers of suppliers' shifting the risk and speculating. It can lead to production disorder, inventory increases, cost heavier. Characters of all kinds of congestion risks are as table 1 showed. Congestion risk can decrease the business transmission efficiency and break the present network relationship. Furthermore, the scale of network shrinks. Generally speaking, congestion risk is the premonition of rigescence risk and decline risk.

Table 1. Types of Congestion Risks

\begin{tabular}{|c|c|c|c|}
\hline $\begin{array}{l}\text { Basis for } \\
\text { classificati } \\
\text { on }\end{array}$ & $\begin{array}{l}\text { Congestion } \\
\text { types }\end{array}$ & Connotation & Example \\
\hline \multirow{3}{*}{$\begin{array}{l}\text { According } \\
\text { to the types } \\
\text { of } \\
\text { transmittin } \\
\text { g } \\
\text { material }\end{array}$} & $\begin{array}{l}\text { logistic } \\
\text { congestion }\end{array}$ & $\begin{array}{l}\text { Logistic congestion risk is } \\
\text { caused by going beyond the } \\
\text { limit of demand quantity of } \\
\text { product, material, component } \\
\text { in enterprises. }\end{array}$ & $\begin{array}{c}\text { Supply exceeds } \\
\text { demand, market downturn }\end{array}$ \\
\hline & $\begin{array}{l}\text { (Part)Capit } \\
\text { al } \\
\text { congestion }\end{array}$ & $\begin{array}{l}\text { Part capital congestion } \\
\text { results from productivity of } \\
\text { capital resources of individual } \\
\text { product, enterprise or } \\
\text { industry far below reasonable } \\
\text { ratio and especially costly. }\end{array}$ & $\begin{array}{l}\text { Ratio of manufacturing } \\
\text { costs of obsolete equipment } \\
\text { in heavy industrial cluster is } \\
\text { too high, which produces } \\
\text { backward in technology }\end{array}$ \\
\hline & $\begin{array}{l}\text { Informatio } \\
\mathrm{n} \\
\text { congestion }\end{array}$ & $\begin{array}{l}\text { Information congestion is } \\
\text { congestion that caused by } \\
\text { blocked } \\
\text { communication information } \\
\text { between the upstream and } \\
\text { downstream enterprises of } \\
\text { supply chain in industry } \\
\text { cluster. }\end{array}$ & $\begin{array}{l}\text { Crisis of confidence } \\
\text { caused by moral hazard and } \\
\text { principal -agency risk }\end{array}$ \\
\hline \multirow{3}{*}{$\begin{array}{l}\text { According } \\
\text { to the } \\
\text { affected } \\
\text { scope of } \\
\text { transmitted } \\
\text { object }\end{array}$} & $\begin{array}{l}\text { Node } \\
\text { congestion }\end{array}$ & $\begin{array}{l}\text { Node congestion results } \\
\text { from individual node } \\
\text { enterprise shorting of the } \\
\text { capacity of business volume } \\
\text { and becoming bottleneck in } \\
\text { supply chain of industry } \\
\text { cluster. }\end{array}$ & $\begin{array}{l}\text { Overloading } \\
\text { environmental capacity of } \\
\text { attractions leads to resources } \\
\text { destroyed in tourism } \\
\text { industry cluster. }\end{array}$ \\
\hline & $\begin{array}{l}\text { Channel } \\
\text { congestion }\end{array}$ & $\begin{array}{l}\text { The node enterprises in } \\
\text { the same channel continuously } \\
\text { appear short of handle } \\
\text { capacity, even appear } \\
\text { enlargement phenomenon. }\end{array}$ & $\begin{array}{l}\text { Stock is too much } \\
\text { because of bullwhip effect. }\end{array}$ \\
\hline & $\begin{array}{l}\text { Same tier } \\
\text { of } \\
\text { enterprises } \\
\text { congestion }\end{array}$ & $\begin{array}{l}\text { A } \\
\text { phenomenon caused by node } \\
\text { enterprises in the same tier } \\
\text { supplier or industry being too } \\
\text { much }\end{array}$ & $\begin{array}{l}\text { Many hotels in the city } \\
\text { have high vacancy rates. }\end{array}$ \\
\hline
\end{tabular}




\subsubsection{Rigescence Risk}

Rigescence risk is caused by regional lock-in effect, inbreeding and path dependence in industry cluster itself. Rigescence risk can weaken the innovation ability of industry cluster, decline the robust, and enhance the closure and fragility. Ultimately, it will lead to low efficiency of supply chain network in whole industry cluster.

Because of exchanging logistic flow, information flow, knowledge flow, labor flow and capital flow among enterprises for a long time, nodes of enterprises in cluster can form a stable and continual relationship. At the same time, three kinds of negative phenomena will appear: regional lock-in effect, inbreeding and path dependence. Regional lock-in effect is an effect that a stable professional division relationship, organization system and industrial regulation have formed with strong grounding system and inertia force in the industry. A cluster may be short of active effect because of lacking opportunity to contacting with those enterprise located out of this cluster because of the regional lock-in effect. Inbreeding in industry cluster is defined as the enterprises continuously establishing in the cluster, there are so many classmates, relations, acquaintances in the complex network, and the same types of enterprises have the same strategies. Path dependence in industry cluster is defined as a kind of positive feedback mechanism, whenever it works, even the environment has changed a lot, and it will not be substituted by other potential and better systems. If one or several negative phenomena exist at the same time, it will hold back the process of restructure and innovation. In a rigescence-seriously industry cluster, there are some negative facts such as moral hazard, adverse selection, hitchhike phenomenon, and lemon market, which will reduce the network efficiency, enhance the vulnerabilities, and give rise to decline risk.

\subsubsection{Decline Risk}

Decline risk is defined as a risk that in the beginning congestion and rigescence risk influence the network and have not been reasonably controlled, then network vulnerability strengthened, after that continuously failure take place and lead to the chain crack in succession, finally network scale and structure turn to worse or drown out in the condition of negative environment. Some external factors such as enterprise competition, political factors, technology progress, and market demand disappearing and monetary policy changing usually induce the decline risk. In a long term, the decline risk influence is seriously. It can cause leading industry transferring and industry cluster dismissing.

\subsection{C-R-D Risk Transmission Mechanism}

There is a transmission mechanism among congestion, rigescence and decline risk. Three kinds of risks drive and strengthen each other. Congestion risk is easy to rise because of slow-speed information transmission and inaccurate prediction in the beginning of the industry cluster development, as Figure 2 shows. Negative influence of local lock-in effect, inbreed and path independence emerge, and rigescence risk becomes the main risk of complex supply chain network with the development and mature of industry cluster. Meanwhile, congestion risk continuously boosts the influential role of rigescence risk. Factors like enterprises contest, technology progress and demand disappearing emerge quickly with the industry cluster stepping into mature late period, and decline risk becomes the main risk of the supply chain network in industry cluster with the driving of congestion and rigescence risk. At this time, industry cluster is in dangerous period and the cluster would degrade or break up if the situation is not being controlled in time. 


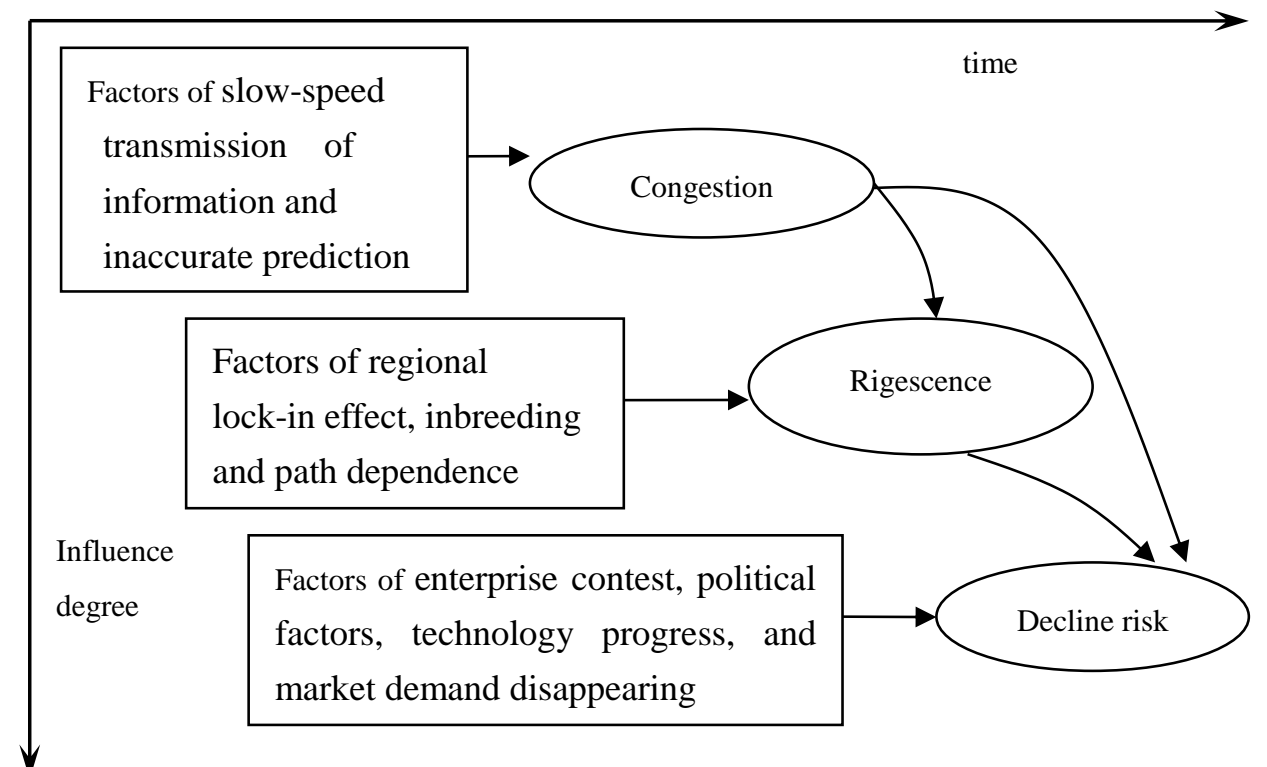

Figure 2. Transmission Mechanism of C-R-D Risk

\section{C-R-D Risk Measurement Model of Complex Supply Chain Network in Industry Cluster}

In order to measure the influential degree of the three kinds of risks, C-R-D risk measurement model is established based on the statistic characteristic of the complex network theory. Therefore, the model is defined as Degree of Risk Influence of Supply Chain Integration in Industry Cluster, namely DRSC:

$$
D R S C=\{D C, D R, D D\}
$$

$D C$ :influential degree of congestion risk;

$D R$ :influential degree of rigescence risk;

$D D$ :influential degree of decline risk

\subsection{Measurement of $D C$}

$D C$ is divided into node congestion degree $\left({ }^{D C}{ }_{j}\right)$, channel congestion degree $\left(D^{D C_{l}}\right)$, and maximum of the same tier industry congestion degree $\left({ }^{D C}{ }_{g}\right)$.

Node congestion degree $\left({ }^{D C}{ }_{j}\right)$ is defined as a ratio of number of nodes in supply chain of the industry cluster to number of congestion nodes, and node degree is weight coefficient. As follows:

$$
D C_{j}=\frac{\sum_{i=1}^{n} d(i) a}{\sum_{i=1}^{n} d(i)} \begin{cases}a=1, \text { when } & k(i)>k_{c}(i) \\ a=0, \text { when } & k(i) \leq k_{c}(i)\end{cases}
$$

Among which, ${ }^{D C}{ }_{j} \in[0,1] . d^{d(i)}$ denotes degree of node ${ }^{i},{ }^{k(i)}$ denotes the actual business volume of node ${ }^{i}, k_{c}(i)$ denotes congestion critical volume of node ${ }^{i}, n$ denotes number of nodes. In formula $(2),{ }^{d(i)}$ indicates the relationship between the nodes with different degree and the other nodes. The larger the node degree is, the more contribution to the congestion degree is. If ${ }^{k(i)}$ is larger than $k_{c}^{(i)}$, congestion risk 
would take place because the business volume is larger than the critical volume. Logistic-flow (include product-flow and material-flow) congestion can be expressed by inventory level, which is calculated by the differences between sales volume and production capacity. If the value of inventory level is larger than the critical value, the congestion would take place. Information congestion can be expressed by quantity of information distortion, namely, it reflects the differences between volume of total demand information and volume of information that the nodes have gained. Capital congestion can be expressed by ratio of sales cost, which can be calculated by differences between actual and critical sales cost ratio. ${ }^{D C}{ }_{j}=0$ means there is no congestion risk. $0<D C{ }_{j} \leq 1$ means there is congestion risk. The larger the value of $D{ }_{j}$ is, the heavier the influential degree is.

Channel congestion degree is defined as a ratio of number of congestion channels which have continuous congestion nodes( no less than two congestion nodes)to total number of the channels of supply chain in industry cluster. The formula is:

$$
D C_{l}=\frac{\sum_{i=1}^{n} b}{\sum_{i=1}^{n} B}
$$

When continuous congestion nodes arise, then $b=1$, otherwise $b=0$. Among which, $D C_{l} \in[0,1]$. $B$ means the total number of the channels of supply network in cluster. A channel indicates one supply chain in the cluster. The channel is easy to break because of the nodes (enterprises) being continuously in the state of congestion. Channel congestion degree indicates the influence of risk on the supply chain. The larger the $D_{l}$ is, the heavier the influence of the risk is.

Maximum congestion degree of the same industry is defined as the maximum value of the suppliers in the same tier. The formula is

$$
D C_{g}=\max \left(D C_{g}^{(1)}, D C_{g}^{(2)}, \cdots D C{ }_{g}^{(p)}{ }_{g} \cdots\right)
$$

Suppliers are in different tiers in supply network of industry cluster. For example, tier-one suppliers and tier-two suppliers. Suppliers in the same tier belong to the same industry. If the competition in the same tier is stiff because there are too many enterprises in the same industry, the crisis of this industry may take place, which would cause the whole network in chaos. Among them, the industry that is in the most heavily state of congestion will face the heaviest risk. Therefore, the maximum value of the congestion degree of all kinds of suppliers was chosen as the same industrial congestion degree of supply chain network.

The formula is

$$
D C_{g}^{(p)}=\frac{\sum k^{(p)}(i)}{\sum k^{(p)}{ }_{c}(i)}-1
$$

Among which, ${ }^{D C}{ }_{g} \geq 0$, The superscript ${ }^{(p)}$ means different tiers of suppliers, $\Sigma k^{(p)}(i)$ means sum of actual volume of tier ${ }^{p}$ suppliers, ${ }^{\left(p k^{(p)}{ }_{c}(i)\right.}$ means sum of critical volume of tier $p$ suppliers. $D C{ }_{g}^{(p)} \leq 0$ means there is no congestion phenomenon in tier g suppliers, while ${ }^{D C}{ }_{g}^{(p)}>0$ indicates the congestion phenomenon has taken place in tier-g suppliers. The larger the ${ }^{D C}{ }_{g}$ is, the heavier the congestion in tier $g$ suppliers is, and the more adverse effect on the connectivity of network. 


\subsection{Measurement of $D R$}

As previously mentioned, rigescence risk is closely related to the situation of local lock-in effect, path dependence, etc. It can cause scarce connectivity in or out of supply network structure. Therefore, degree of rigescence risk includes out-enclose degree $D R{ }_{w}$ and in-enclose degree $D R_{n}$.

Out-enclose degree, DR, is defined as a ratio of number of connection between enterprises in cluster to sum of connection number between one enterprise in cluster and the other enterprise out of cluster. It indicates the comparison between the enclose degree in the cluster and the enclose degree outside of the cluster. The larger the value of DR is, the larger the likelihood the risk takes place. The formula is:

$$
D R_{w}=\frac{e}{e+\sum_{1}^{e(i, j)} c} \quad\left\{\begin{array}{l}
c=1, i \not \subset \Omega_{0}, j \not \subset \Omega_{0} \\
c=0, i \subset \Omega_{0}, j \subset \Omega_{0}
\end{array}\right.
$$

Among which, $D R_{w} \in[0,1] . e(i, j)$ denotes an edge between enterprise $i$ and enterprise $j$ in cluster. $e$ denotes the number of edges among nodes in cluster. $\Omega_{0}$ denotes the area of the industry cluster. $i$ indicates the node (enterprise) which edge $e(i, j)$ begins with, $j$ indicates the node (enterprise) which edge $e(i, j)$ ends with. Contact intensity is not considered in formula(5), and we presume that every edge has equal numbers of contact intensity. If contact intensity is of great difference, edges should be added more rating weight. If the value of $D R_{w}$ is larger and larger, the likelihood of rigescence risk is larger and larger. The critical value should be determined by certain industry. For example, if 0.9 is used as critical value, rigescence risk will take place when $D R_{w}>0.9$.

In-enclosed degree is define as a degree of communication scarcity in cluster, the formula is

namely

$$
\begin{aligned}
& D R_{n}=1-C=1-\sum_{1}^{n} C_{i} / n \\
& D R_{n}=1-\sum_{1}^{n}\left[\frac{2 e_{i}}{k_{i}\left(k_{i}-1\right)}\right] / n
\end{aligned}
$$

Among which $D R_{n} \in[0,1], C$ denotes the cluster coefficient of supply chain network. $C_{i}$ denotes the cluster coefficient of node $i . k_{i}$ denotes number of correlative enterprises of node $i \cdot e_{i}$ denotes number of edges concerning the correlative enterprises, $k_{i}\left(k_{i}-1\right)$ 12 indicates the maximum possible number of edges concerning correlative enterprises of node $i$. Therefore, the less the value of $C$ is, the weaker the correlative degree is. whereas the larger $D R_{n}$ is, the larger degree of in-enclose is. The weaker the correlative ability among the enterprises in cluster is, the larger the probability of rigescence risk takes place.

\subsection{Measurement of $D D$}

There are two indexes to explain for evaluating the influence degree of decline risk, $D D_{E}$ and $D D_{S}$, namely average efficiency reduction ratio of network and scale reduction ratio of network. Seriate failures can cause node cracking or channel available in supply network because of various factors' influence. Furthermore, it can bring lower average efficiency and scale of network. Therefore, we describe the degree of decline risk influence by $D D_{E}$ and $D D_{S}$.

$D D_{E}$, average efficiency reduction ratio of network is defined as a ratio of efficiency after seriate failures taking place to efficiency in normal situation. The formula is: 


$$
D D_{E}=1-\frac{1 /\left[\frac{1}{n_{1}\left(n_{1}-1\right)} \sum d^{(1)}{ }_{i j}\right]}{1 /\left[\frac{1}{n_{0}\left(n_{0}-1\right)} \sum d^{(0)}{ }_{i j}\right]}
$$

Among which, $D D_{E} \in[0,1] \cdot d^{(0)}{ }_{i j}$ and $d^{(1)}{ }_{i j}$ separately denote the minimum distance between node $i$ and $j$ before and after seriate failures taking place in network. $n_{0}$ and $n_{1}$ separately denote the number of nodes before and after seriate failures in network. The lower the average network efficiency reduction ratio is, the higher the decline risk is.

$D D_{S}$, scale reduction ratio of network is defined as a ratio of number of nodes after seriate failures taking palace to number of nodes in normal state in network, all number of nodes is weighted by degree number. The formula is:

$$
D D_{S}=1-\frac{d^{(1)}(i) N_{1}}{d^{(0)}(i) N_{0}}
$$

Among which, $D D_{s} \in[0,1] . N_{1}$ means the number of nodes in maximal connected subgraph after seriate failures taking place, whereas $N_{0}$ means the number of nodes in maximal connected subgraph in normal situation. $d^{(1)}(i)$ and $d^{(0)}(i)$ separately indicate the degree of nodes in maximal connected subgraph after seriate failures taking place and in normal situation. The larger value of the $D D{ }_{S}$ is, the higher the decline risk is.

Therefore, from formula (1) and (2) - (8), Degree of Risk Influence of Supply Chain Integration in Industry Cluster( $D R S C$ ) is as follows:

$$
D R S=\left\{D C_{j}, D C_{l}, D C_{g}, D R_{w}, D R_{n}, D D_{E}, D D_{s}\right\}
$$

\section{Numerial Example}

A supply chain network in industry cluster such as figure 1 shows. Among which $A_{02}$, $A_{03}, B_{01}, C_{01}, C_{02}$ are congestion nodes (just as grey nodes shown in Figure 1). Value of $d(i), k(i), k_{c}(i), a$ of different nodes is as follows:

Table 2. Value of $d(i), k(i), k_{c}(i), a$

\begin{tabular}{ccccc|ccccc}
\hline nodes & $d(i)$ & $k(i)$ & $k_{c}(i)$ & $a$ & nodes & $d(i)$ & $k(i)$ & $k_{c}(i)$ & $a$ \\
\hline$A_{01}$ & 4 & 6 & 7 & 0 & $D_{01}$ & 3 & 8 & 12 & 0 \\
$A_{02}$ & 8 & 12 & 10 & 1 & $D_{02}$ & 2 & 6 & 7 & 0 \\
$A_{03}$ & 5 & 8 & 7 & 1 & $D_{03}$ & 3 & 6 & 7 & 0 \\
$B_{01}$ & 4 & 24 & 18 & 1 & $D_{04}$ & 1 & 3 & 4 & 0 \\
$B_{02}$ & 7 & 11 & 14 & 0 & $D_{05}$ & 1 & 4 & 5 & 0 \\
$C_{01}$ & 8 & 36 & 30 & 1 & $D_{06}$ & 3 & 10 & 12 & 0 \\
$C_{02}$ & 8 & 32 & 30 & 1 & $D_{07}$ & 2 & 8 & 11 & 0 \\
\hline
\end{tabular}

\subsection{Calculation of Degree of Congestion Risk}

In the application we can calculate the value of $d(i)$ and $a$ by using the formula (2): 


$$
D C_{j}=\frac{\sum_{i=1}^{n} d(i) a}{\sum_{i=1}^{n} d(i)}=\frac{36}{69}=0.523
$$

So degree of node congestion is 523. From it we can conclude that though the number of nodes is small, the node congestion degree is large, which is because of the core role of the congestion nodes in supply chain network.

To illustrate the different channels and their situations of continuous congestion in Figure 1, as Table 3 shows, there are 23 channels in complex network in cluster in figure 1. Among them six channels have the phenomenon of node congestion (at least two continuously node in congestion state). Therefore, according to the formula (3):

$$
D C_{l}=\frac{\sum_{i=1}^{n} b}{\sum_{i=1}^{n} B}=\frac{6}{23}=0.261
$$

So congestion degree of channel is 0.261 .

As Figure 1 shows, suppliers have $A, B, C, D$ four tiers. We can calculate the value of $\Sigma k^{(p)}(i)$ and $\Sigma k^{(p)}{ }_{c}(i)$ according to Table 2. Among which $\Sigma k^{(A)}(i)$ $=6+12+8=26, \quad \Sigma k^{(B)}(i)=35, \Sigma k^{(C)}(i)=68, \Sigma k^{(D)}(i)=45, \Sigma k^{(A)}{ }_{c}(i)=7+10+7=24, \Sigma k^{(B)}{ }_{c}(i)$ $=32, \Sigma k^{(C)}{ }_{c}(i)=60, \Sigma k^{(D)}{ }_{c}(i)=68$. So

Table 3. Channels and Congestion Degree of Channels

\begin{tabular}{cll|cll}
\hline $\begin{array}{c}\text { Serial } \\
\text { number }\end{array}$ & \multicolumn{1}{c|}{ channels } & $b$ & $\begin{array}{c}\text { Serial } \\
\text { number }\end{array}$ & \multicolumn{1}{c}{ channels } & $b$ \\
\hline 1 & $A_{01}-D_{01}$ & 0 & 13 & $A_{02}-B_{02}-D_{04}$ & 0 \\
2 & $A_{01}-B_{01}-C_{01}-D_{02}$ & 0 & 14 & $A_{02}-D_{06}$ & 0 \\
3 & $A_{01}-B_{01}-C_{01}-D_{03}$ & 1 & 15 & $A_{03}-B_{02}-C_{01}-D_{02}$ & 0 \\
4 & $A_{02}-B_{01}-C_{01}-D_{02}$ & 1 & 16 & $A_{03}-B_{02}-C_{01}-D_{03}$ & 0 \\
5 & $A_{02}-B_{01}-C_{01}-D_{03}$ & 1 & 17 & $A_{03}-B_{02}-C_{02}-D_{01}$ & 0 \\
6 & $A_{02}-B_{02}-C_{01}-D_{02}$ & 0 & 18 & $A_{03}-B_{02}-C_{02}-D_{02}$ & 0 \\
7 & $A_{02}-B_{02}-C_{01}-D_{03}$ & 0 & 19 & $A_{03}-B_{02}-C_{02}-D_{03}$ & 0 \\
8 & $A_{02}-B_{02}-C_{02}-D_{01}$ & 0 & 20 & $A_{03}-B_{02}-C_{02}-D_{05}$ & 0 \\
9 & $A_{02}-B_{02}-C_{02}-D_{02}$ & 0 & 21 & $A_{03}-B_{02}-C_{02}-D_{06}$ & 1 \\
10 & $A_{02}-B_{02}-C_{02}-D_{03}$ & 0 & 22 & $A_{03}-D_{06}$ & 1 \\
11 & $A_{02}-B_{02}-C_{02}-D_{05}$ & 0 & 23 & $A_{03}-D_{07}$ & 0 \\
12 & $A_{02}-B_{02}-C_{02}-D_{06}$ & 1 & & & \\
\hline
\end{tabular}

$$
\begin{gathered}
D C{ }_{g}^{(A)}=\frac{\sum k^{(A)}(i)}{\sum k^{(A)}{ }_{c}(i)}-1=\frac{26}{24}-1=0.083 \\
D C_{g}^{(B)}=\frac{\sum k^{(B)}(i)}{\sum k^{(B)}{ }_{c}(i)}-1=\frac{35}{32}-1=0.094 \\
D C{ }_{g}^{(C)}=\frac{\sum k^{(C)}(i)}{\sum k^{(C)}{ }_{c}(i)}-1=\frac{68}{60}-1=0.133 \\
D C{ }_{g}^{(D)}=\frac{\sum k^{(D)}(i)}{\sum k^{(D)}{ }_{c}(i)}-1=\frac{45}{68}-1=0
\end{gathered}
$$


The congestion degree of $A, B, C, D$ suppliers in different tiers respectively are 0.083 , 0.094, 0.013, 0 .

According to formula (4),

$$
D C_{g}=\max (0.083,0.094,0.133,0)=0.133
$$

So congestion degree of $C$ tier suppliers is the highest one, the industry which those suppliers lie in has the highest congestion risk.

\subsection{Calculation of Degree of Rigescence Risk}

One assumes that every contact intensity between enterprises of the same edge is equivalent in Figure 1, and without consideration of weight coefficient As Figure 1 shows, number of edge between nodes in industry cluster is 24 , namely $e=24$. Number of edges which connects the enterprises from industry cluster to other areas is 11. So according to formula (5), the out-enclose degree is as follows:

$$
D R_{w}=\frac{e}{e+\sum_{1}^{e(i, j)} c}=\frac{24}{24+11}=\frac{24}{35}=0.6857
$$

Assume the critical value of the out-enclose degree of rigescence risk is 0.85 , then $D R_{w}<0.85$, there is not rigescence risk. But if the critical value is less than 0.68 , the rigescence risk has arisen.

As Figure 1 shows, we calculate the value of $e_{i}, k_{i}\left(k_{i}-1\right) / 2$ and $C_{i}$ based on the connective nodes. Table 4 shows these values. Therefore, according to formula (6), in-enclose degree is:

$$
D R_{n}=1-\sum_{1}^{n}\left[\frac{2 e_{i}}{k_{i}\left(k_{i}-1\right)}\right] / n=1-\frac{0.2+0.2+0.1+0.333+0.333}{14}=0.917
$$

Table 4. Value of $e_{i}, k_{i}\left(k_{i}-1\right) / 2, C_{i}$

\begin{tabular}{cccc|cccc}
\hline nodes & $e_{i}$ & $k_{i}\left(k_{i}-1\right) / 2$ & $C_{i}$ & nodes & $e_{i}$ & $k_{i}\left(k_{i}-1\right) / 2$ & $C_{i}$ \\
\hline$A_{01}$ & 0 & 2 & 0 & $D_{01}$ & 1 & 3 & 0.333 \\
$A_{02}$ & 2 & 10 & 0.2 & $D_{02}$ & 0 & 1 & 0 \\
$A_{03}$ & 2 & 6 & 0.333 & $D_{03}$ & 0 & 1 & 0 \\
$B_{01}$ & 0 & 3 & 0 & $D_{04}$ & 0 & 0 & 0 \\
$B_{02}$ & 2 & 10 & 0.2 & $D_{05}$ & 0 & 0 & 0 \\
$C_{01}$ & 1 & 10 & 0.1 & $D_{06}$ & 0 & 3 & 0 \\
$C_{02}$ & 0 & 10 & 0 & $D_{07}$ & 0 & 1 & 0 \\
\hline
\end{tabular}

So the in-enclose degree is 0.917 . This value is rather large. Therefore, from the perspective of rigescence risk, if the supply chain network is enclosed in cluster, the contact ability would low and the influence effect would be obvious on the supply chain network in the industry cluster.

\subsection{Calculation of Degree of Decline Risk}

As previously mentioned, decline risk usually emerges after the seriate failures continuously take place. For instance, failure takes place at $B_{01}$ and $C_{01}$ (Figure 1) continuously in supply chain network. $B_{01}$ and $C_{01}$ withdraw from the industry, their 
edges with other nodes crack, just as Figure 3 shows:

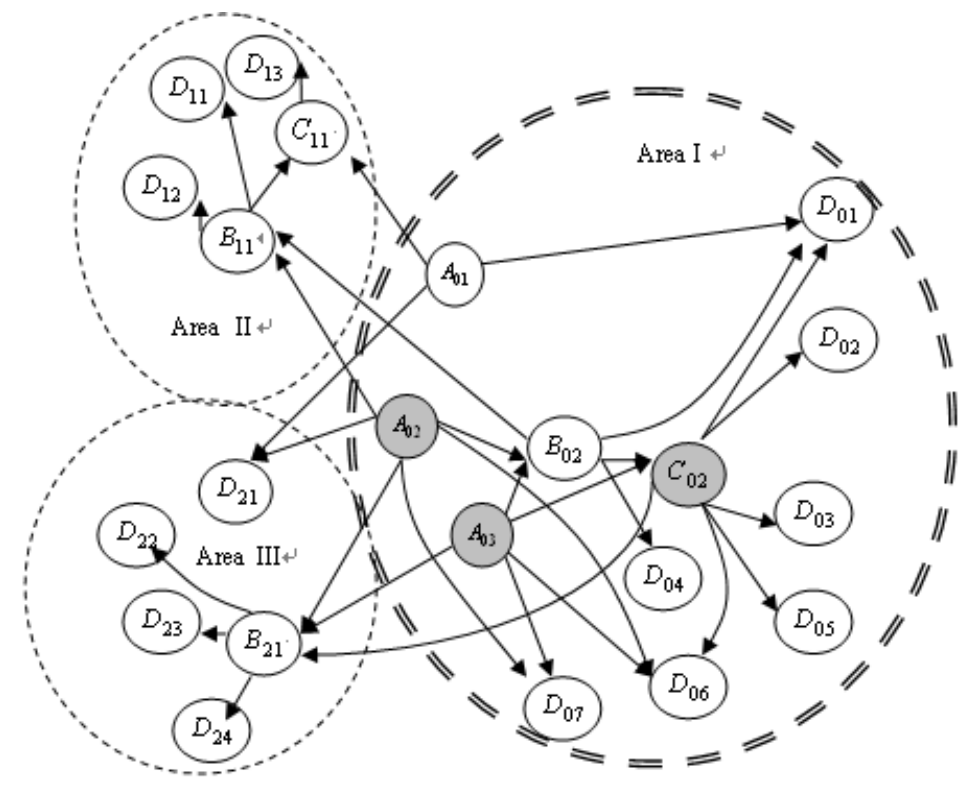

Figure 3. Complex Network of Supply Chain in Industry Cluster after Cascading Failure

According to Figure 1 and Figure 3, we can calculate the upper triangular matrix of the shortest distance $d^{(0)}$ and $d^{(1)}$, which can be described as

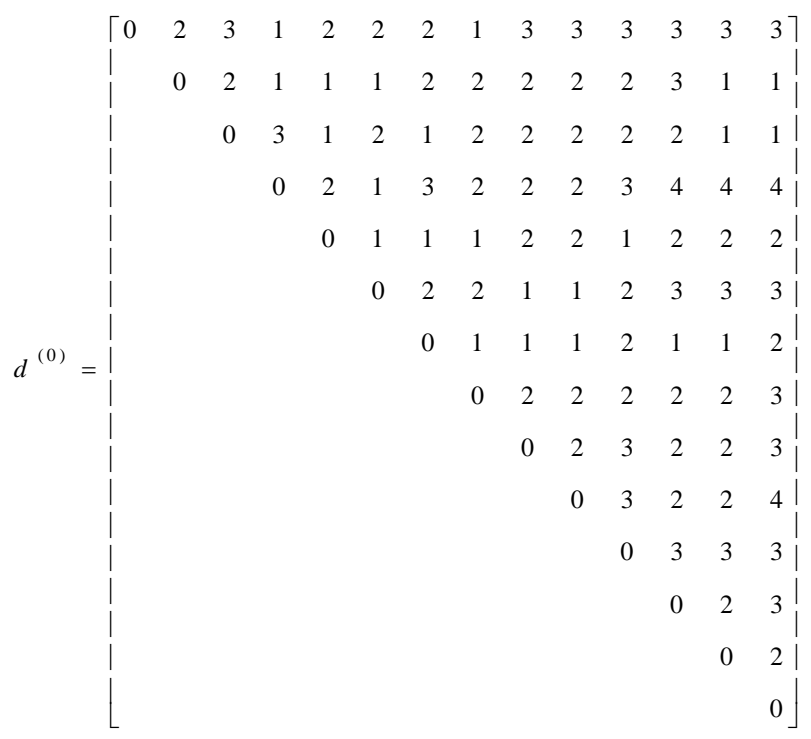




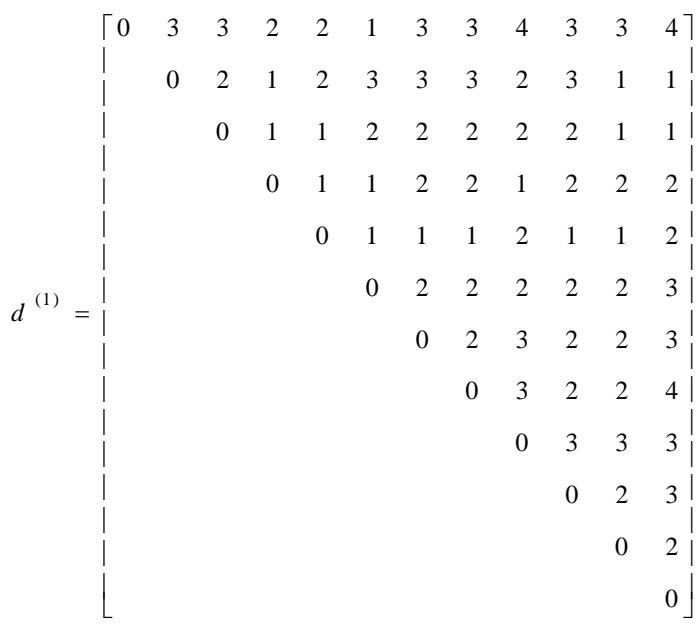

The number of enterprise nodes before a failure is 14 and after a failure is 12 , namely $n_{0}=14, n_{1}=12$, so according to formula $(8)$,

$$
D D_{E}=1-\frac{1 /\left[\frac{1}{n_{1}\left(n_{1}-1\right)} \sum d^{(1)}{ }_{i j}\right]}{1 /\left[\frac{1}{n_{0}\left(n_{0}-1\right)} \sum d^{(0)}{ }_{i j}\right]}=1-\frac{1 /\left[\frac{1}{132} \times 280\right]}{1 /\left[\frac{1}{182} \times 378\right]}=0.02
$$

And thus, average efficiency reduction ratio of network is 0.02 .

See Figure 1 and Figure 3, $N_{0}=14$ and $N_{1}=12$. and $d^{(1)}(i)=16, d^{(0)}{ }^{(i)}=24$. According to formula (9), $D D{ }_{S}$ is:

$$
D D_{s}=1-\frac{d^{(1)}(i) N_{1}}{d^{(0)}(i) N_{0}}=1-\frac{16 \times 12}{24 \times 14}=0.429
$$

Thus reduction ratio of network scale is 0.429 . So we can conclude that decline risk causes little reduction of average efficiency of network, but highly reduces the scale of network, which lead to declining in excess of $40 \%$.

\section{Conclusion and Discussion}

This study focused on the industrial cluster risk from supply chain and complex network perspective. The definitions and measurement of 3 kinds of industrial risk (Congestion risk, Rigescence Risk and Decline risk) were proposed. Finally, the appropriateness and applicability of the masurement model were confirmed by a numerial example.

The model is applicable that it can be used in evaluating the risk influence to the complex supply chain network in industry cluster by calculation example. In order to using DRSC model, we should make a survey to acquire the complex network structure of supply chain in cluster and consult the database of actual and critical congestion business volume. Because of the similarity of the structure of supply chain network in industry, DRSC model realizes the goal that analyze the influential degree of supply chain risk in cluster from network structure and its evolution perspective, and it becomes an effective tool to control and forecast the risk of industry cluster. This model not only can be applied in comparing among different industry cluster in the same time, but also can be applied in describing the fluctuations when the industry cluster evolves accompany with risk. Because DRSC model is focused on researching the degree of risk influence from the perspective of structure evolution of network, it is benefit for the government adjusting 
policies of avoiding risk to the industry structure with method of optimizing the structure. However, the model has its limitations and inadequateness. For instance, we have never considered some factors such as lacking ability of innovation when we analyze the rigescence. We have not concerned about the complex network of supply chain in cluster with weight coefficient. Meantime, it is important in future research to study on adjustable variable weight coefficient to control the risk based on the supply chain complex network.

\section{Acknowledgment}

This paper is supported by Research Funding of Hebei Province Education Department (ZC2016025), Hebei Province Science and Technology Plan Projects (154576233), Independent Research Funding for Junior Faculty of Yanshan University (14SKB001) and Yanshan University Postdoctoral Science Foundation (B838).

\section{References}

[1] Dirk Helbing. Physica A, 1, 363 (2006)

[2] Marco Laumanns, Erjen Lefeber. PhysicaA, 1,363 (2006)

[3] Christian Kuhnert,Dirk Helbing. Physica A, 1,363 (2006)

[4] Guo Jin-Li. Acta Physical Sinica.8, 55(2006)

[5] Zhang Xinrui,Wang Hengshan. Industry Technology and Economic,2, 27(2008)

[6] TICHY G.Clusters:less dispensable and more risky than ever,in clusters and regional specialization. Pion Limited, London(1998)

[7] Cai Ning, Wu Jiebing, Yin Ming. Economic Geography, 3, 26 (2006)

[8] Ritehie B.,Brindley C.,MorrisJ.,Peet S.. Managing risk within the supply chain. Proceedings of the 9th International IPSERA, (2000), Ontario

[9] HarlandC., Brencheley H., Walker H.. Journal of purchasing and Supply Management, 2, 9 (2003)

[10] CavinatoJ.L.. International Journal of Physical Distribution \& Logistics Management, 5, 34 (2004)

[11] Jukka H., Iris K., Urho P., Veli-MattiV, Markku T..International Journal of Produetion Economies,90(2004)

[12] Saxenian, Anna Lee. Regional advantage:Culture and competition in silicon valley and route 128. HarvardUniversityPress, Cambridge(1994)

[13] Cai Ning,Yang Shuangzhu, Wu Jiebing. China Industrial Economy, 4(2003)

[14] Cai Ning, Xu Mengzhou. Journal of Chongqing University(Social Science Edition) ,5, 14(2008).

[15] Wang Faming,Liu Chuangeng. Commercial Research,11 (2009)

[16] Chen Wei, Zhou Wen and Lang Yifu. Management Review, 20, 27(2015)

[17] Ernst \& Young. Risk in the supply chain survey, ( 2003)

[18] Harland C, Brencheley H, Walker H. Journal of purchasing and Supply Management, 2, 9 (2003)

[19] Dirk Helbing. Physica A, 1, 363(2006)

[20] Marco Laumanns, Erjen Lefeber. PhysicaA, 1,363 (2006)

[21] Christian Kuhnert,Dirk Helbing. Physica A, 1,363 (2006)

[22] Guo Jin-Li. Acta Physical Sinica.8, 55(2006)

[23] Zhang Xinrui,Wang Hengshan. Industry Technology and Economic, 2, 27(2008)

[24] TICHY G.Clusters:less dispensable and more risky than ever,in clusters and regional specialization. Pion Limited, London(1998)

[25] Cai Ning, Wu Jiebing,Yin Ming. Economic Geography, 3, 26 (2006)

[26] Ritehie B.,Brindley C.,MorrisJ.,Peet S.. Managing risk within the supply chain. Proceedings of the 9th International IPSERA, (2000), Ontario

[27] HarlandC., Brencheley H., Walker H.. Journal of purchasing and Supply Management, 2, 9 (2003)

[28] CavinatoJ.L.. International Journal of Physical Distribution \& Logistics Management, 5, 34 (2004)

[29] Jukka H., Iris K., Urho P., Veli-MattiV， Markku T..International Journal of Produetion Economies,90(2004)

[30] Saxenian, Anna Lee. Regional advantage:Culture and competition in silicon valley and route 128. HarvardUniversityPress, Cambridge(1994)

[31] Cai Ning, Yang Shuangzhu,Wu Jiebing. China Industrial Economy, 4(2003)

[32] Cai Ning, Xu Mengzhou. Journal of Chongqing University(Social Science Edition) ,5, 14(2008).

[33] Wang Faming,Liu Chuangeng. Commercial Research,11 (2009)

[34] Chen Wei, Zhou Wen and Lang Yifu. Management Review, 20, 27(2015)

[35] Ernst \& Young. Risk in the supply chain survey,( 2003)

[36] Harland C, Brencheley H, Walker H. Journal of purchasing and Supply Management, 2, 9 (2003) 


\section{Authors}

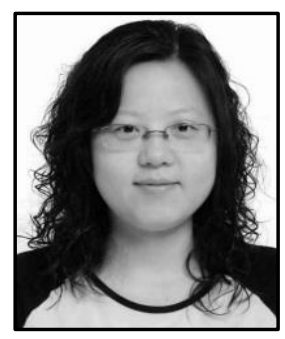

Haiju Hu, she received her Ph.D. degree in decision science and managerial economics from the Chinese University of Hong Kong, Hong Kong. She is currently a lecture in the Economics and Management School at Yanshan University, China. Her research area are supply chain management, quality management and complex network.

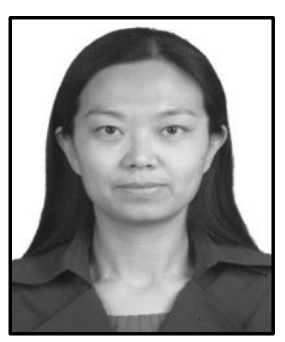

Bo Shu, received Doctor Degree in Management and currently is a professor of Yanshan University in China. Her current research is about strategy management, Supply Chain Management, Complex network in industry, etc.

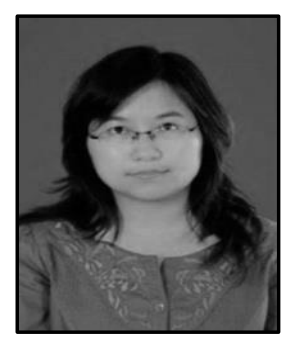

Peng Wang, received her Master degree in Linguistics and currently is an associate professor of Yanshan University. Her current research is about cognition and language acquisition. 